\title{
A Study of Parameters Related to the Etch Rate for a Dry Etch Process Using $\mathrm{NF}_{3} / \mathrm{O}_{2}$ and $\mathrm{SF}_{6} / \mathrm{O}_{2}$
}

\author{
Seon-Geun Oh, ${ }^{1}$ Kwang-Su Park, ${ }^{1}$ Young-Jun Lee, ${ }^{1}$ Jae-Hong Jeon, ${ }^{1}$ \\ Hee-Hwan Choe, ${ }^{1}$ and Jong-Hyun Seo ${ }^{2}$ \\ ${ }^{1}$ School of Electronics, Telecommunications and Computer Engineering, Korea Aerospace University, \\ Goyang 412-791, Republic of Korea \\ ${ }^{2}$ Department of Materials Science and Engineering, Korea Aerospace University, Goyang 412-791, Republic of Korea
}

Correspondence should be addressed to Hee-Hwan Choe; choehh@kau.ac.kr

Received 1 May 2013; Accepted 8 November 2013; Published 4 February 2014

Academic Editor: Mohd Sapuan Salit

Copyright (C) 2014 Seon-Geun Oh et al. This is an open access article distributed under the Creative Commons Attribution License, which permits unrestricted use, distribution, and reproduction in any medium, provided the original work is properly cited.

\begin{abstract}
The characteristics of the dry etching of $\mathrm{SiN}_{x}: \mathrm{H}$ thin films for display devices using $\mathrm{SF}_{6} / \mathrm{O}_{2}$ and $\mathrm{NF}_{3} / \mathrm{O}_{2}$ were investigated using a dual-frequency capacitively coupled plasma reactive ion etching (CCP-RIE) system. The investigation was carried out by varying the RF power ratio $(13.56 \mathrm{MHz} / 2 \mathrm{MHz})$, pressure, and gas flow ratio. For the $\mathrm{SiN}_{x}: \mathrm{H}$ film, the etch rates obtained using $\mathrm{NF}_{3} / \mathrm{O}_{2}$ were higher than those obtained using $\mathrm{SF}_{6} / \mathrm{O}_{2}$ under various process conditions. The relationships between the etch rates and the usual monitoring parameters-the optical emission spectroscopy (OES) intensity of atomic fluorine $(685.1 \mathrm{~nm}$ and $702.89 \mathrm{~nm})$ and the voltages $V_{H}$ and $V_{L}$-were investigated. The OES intensity data indicated a correlation between the bulk plasma density and the atomic fluorine density. The etch rate was proportional to the product of the OES intensity of atomic fluorine $(I(\mathbf{F}))$ and the square root of the voltages $\left(\sqrt{V_{h}+V_{l}}\right)$ on the assumption that the velocity of the reactive fluorine was proportional to the square root of the voltages.
\end{abstract}

\section{Introduction}

In the fabrication of flat panel displays, $\mathrm{SF}_{6}$ is used to etch various thin films. $\mathrm{NF}_{3}$, on the other hand, is used for two reasons in particular. First, it is used to etch Si. Focus is put on films such as $\mathrm{SiO}_{2}$ and $\mathrm{Si}_{3} \mathrm{~N}_{4}$, which are used for semiconductor devices [1-7]. Second, $\mathrm{NF}_{3}$ is used to clean the chamber in the plasma enhanced chemical vapor deposition (PECVD) process [8]. Previous studies have looked at the etching characteristics and mechanisms of films with $\mathrm{NF}_{3}$. In these studies, a number of analysis tools, including a quadrupole mass spectrometer (QMS), ellipsometer, X-ray photoelectron spectrometer (XPS), and optical emission spectroscopy (OES), were used. With these studies in mind, this current paper postulates that $\mathrm{NF}_{3}$ could be used as an alternative to $\mathrm{SF}_{6}$ in the dry etching process for flat panel display manufacturing.

The replacement of $\mathrm{SF}_{6}$ with $\mathrm{NF}_{3}$ would offer certain advantages Manufacturers would be able to change the etching gas on demand and would still be able to use existing facilities. Moreover, because of increasing concerns regarding the greenhouse effect, many research groups have looked for gases that could be used to replace $\mathrm{SF}_{6}$ to reduce the global warming potential (GWP). Low GWP gases such as $\mathrm{F}_{2}[9,10]$, $\mathrm{C}_{4} \mathrm{~F}_{8}$ [11], $\mathrm{CHF}_{3} \mathrm{O}_{2}$ [12], $\mathrm{C}_{3} \mathrm{~F}_{8}$ [7], and $\mathrm{C}_{3} \mathrm{~F}_{6} \mathrm{O}$ [13] in the dry etch process have been studied. These investigations indicated that it would be possible to use low GWP gases to replace $\mathrm{SF}_{6}$ in the etching processes. Of importance to this current study, it has also been shown that the use of $\mathrm{NF}_{3}$ would decrease the GWP of the flat panel manufacturing process [14-17].

To evaluate the possibility of replacing $\mathrm{SF}_{6}$ with $\mathrm{NF}_{3}$, the $\mathrm{SiN}_{x}: \mathrm{H}$ dry etching characteristics using $\mathrm{SF}_{6}$ and $\mathrm{NF}_{3}$ were compared. The similarities and dissimilarities between the processes using the two gases were studied. Because simple parameters such as the voltage of the input power and optical emission lines are commonly monitored in manufacturing equipment, the relationships between these parameters and the etch characteristics could be investigated in this work. 


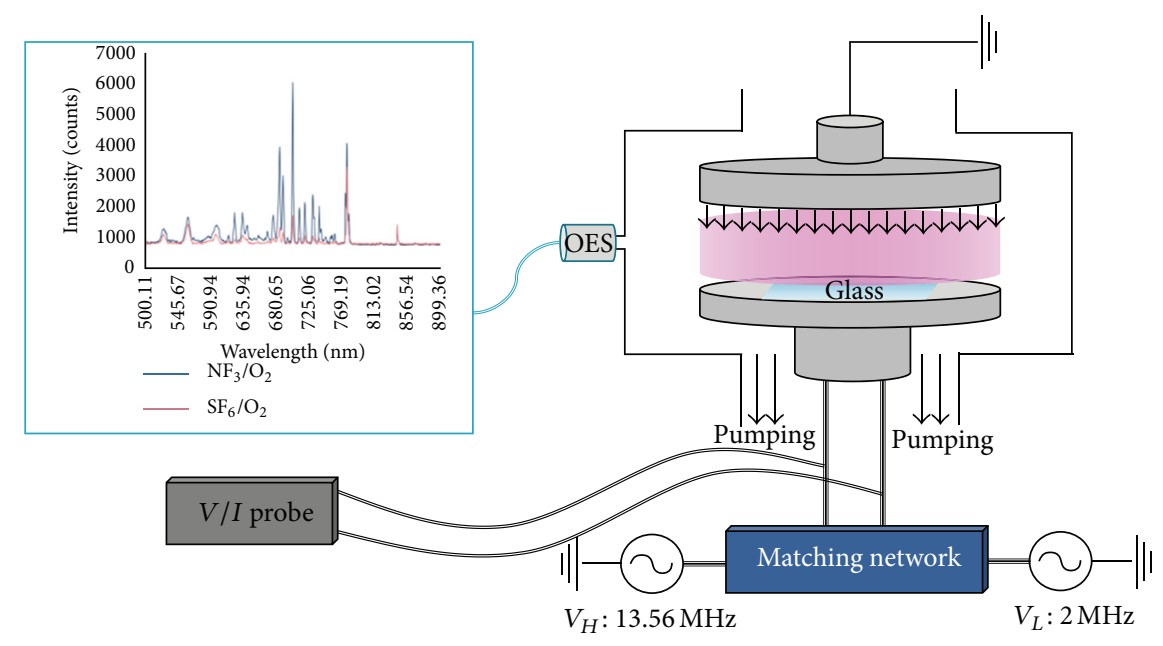

FIgURE 1: Diagram of the dual-frequency CCP-RIE with OES and V-I probe.

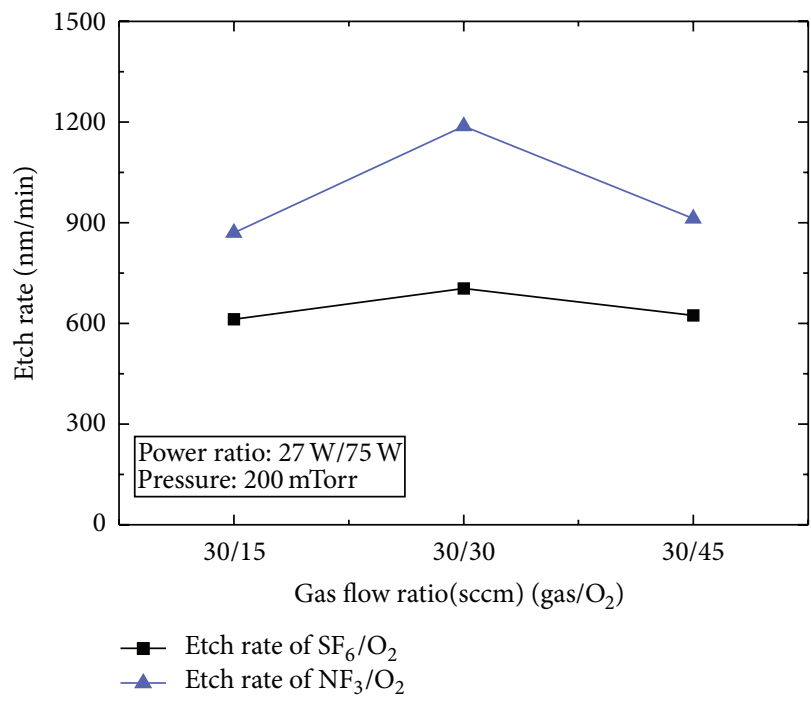

(a)

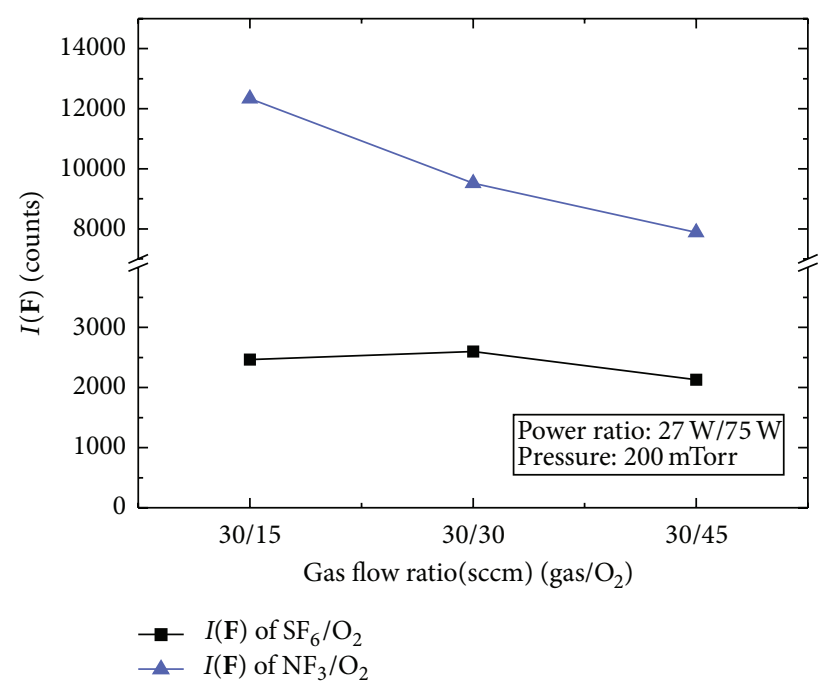

(b)

Figure 2: (a) Etch rates of $\mathrm{SF}_{6} / \mathrm{O}_{2}$ and $\mathrm{NF}_{3} / \mathrm{O}_{2}$ and (b) optical emission intensity of fluorine for $\mathrm{SF}_{6} / \mathrm{O}_{2}$ and $\mathrm{NF}_{3} / \mathrm{O}_{2}$ as a function of gas flow ratio.

In this paper, Section 2 provides details regarding the experimental setup and process conditions. In Section 3, the results and a description of the experiment are presented. Section 4 covers the interpretation and analysis of the results.

\section{Materials and Methods}

The $\mathrm{SiN}_{x}: \mathrm{H}$ film samples were deposited on a glass substrate using PECVD and etched using a dual-frequency CCPRIE system with $\mathrm{SF}_{6} / \mathrm{O}_{2}$ and $\mathrm{NF}_{3} / \mathrm{O}_{2}$ gas mixtures. The reference process conditions consisted of a gas flow ratio (gas/ $\mathrm{O}_{2}$ ) between the fluorine gas $\left(\mathrm{SF}_{6}\right.$ or $\left.\mathrm{NF}_{3}\right)$ and $\mathrm{O}_{2}$ of $30 \mathrm{sccm} / 30 \mathrm{sccm}$, a pressure of $200 \mathrm{mTorr}$, and a dualfrequency power ratio $(13.56 \mathrm{MHz} / 2 \mathrm{MHz})$ of $25 \mathrm{~W} / 75 \mathrm{~W}$.

The gas flow ratio was varied by varying the $\mathrm{O}_{2}$ flow rate from $15 \mathrm{sccm}$ to $45 \mathrm{sccm}$. The pressure was varied from
100 mTorr to 200 mTorr at an interval of 50 mTorr, and the power ratio was changed between values of $25 \mathrm{~W} / 75 \mathrm{~W}$ and $75 \mathrm{~W} / 25 \mathrm{~W}$, where the total power was fixed at $100 \mathrm{~W}$.

The etch rate was measured with a general procedure as follows.

First, the photoresist was deposited on the $\mathrm{SiN}_{x}: \mathrm{H}$ film using the photolithography process, after which the thickness of the deposited photoresist was measured using a surface profiler ( $\alpha$-step). Second, the thickness of the etched film and the oxidized photoresist was measured using the surface profiler after dry etching using a CCP-RIE. Third, the thickness of the etched film was measured using the surface profiler after stripping the oxidized photoresist.

A schematic diagram of the dual-frequency CCP-RIE system for the dry etching process is shown in Figure 1. The optical emissions from the plasma were collected through 


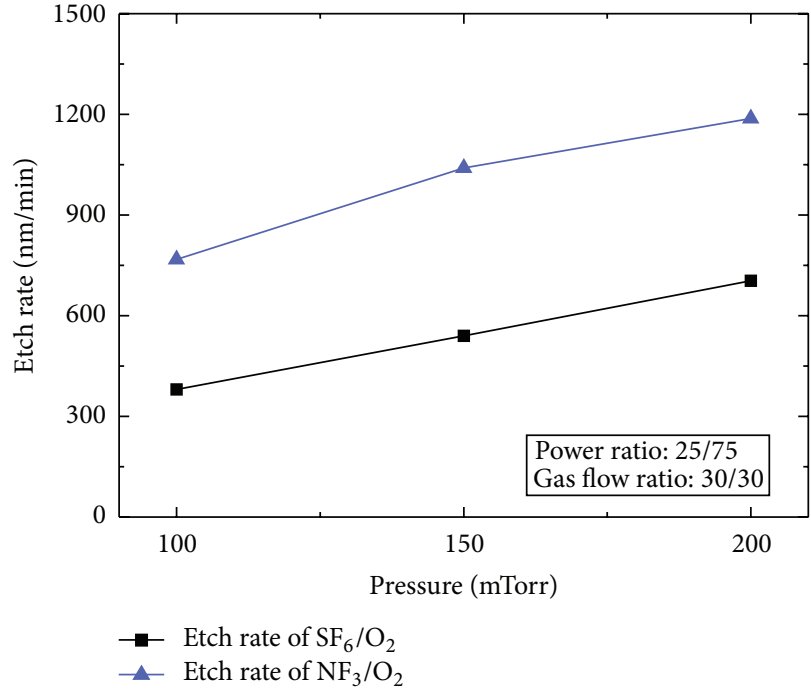

(a)

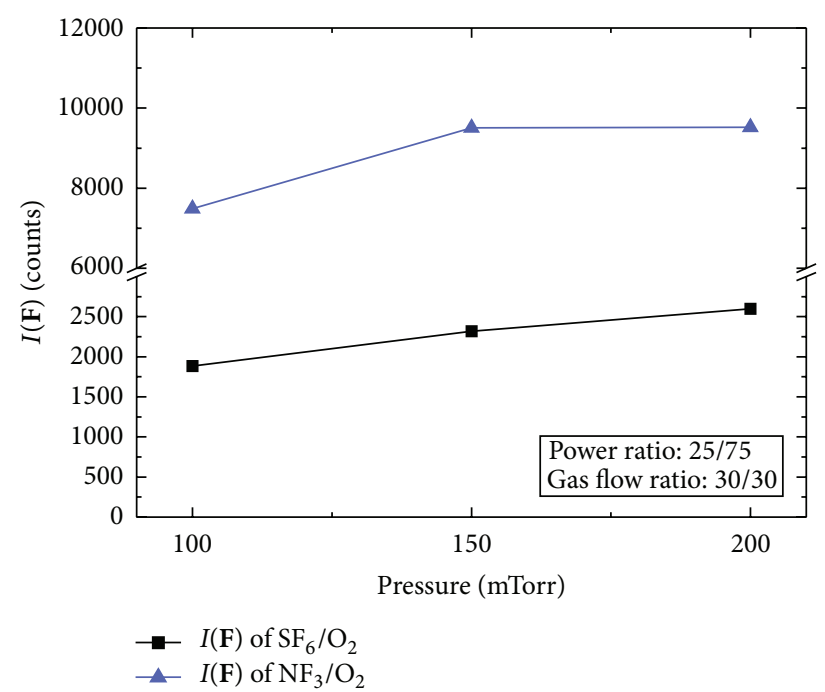

(b)

Figure 3: (a) Etch rates of $\mathrm{SF}_{6} / \mathrm{O}_{2}$ and $\mathrm{NF}_{3} / \mathrm{O}_{2}$ and (b) optical emission intensity of fluorine for $\mathrm{SF}_{6} / \mathrm{O}_{2}$ and $\mathrm{NF}_{3} / \mathrm{O}_{2}$ as a function of pressure.

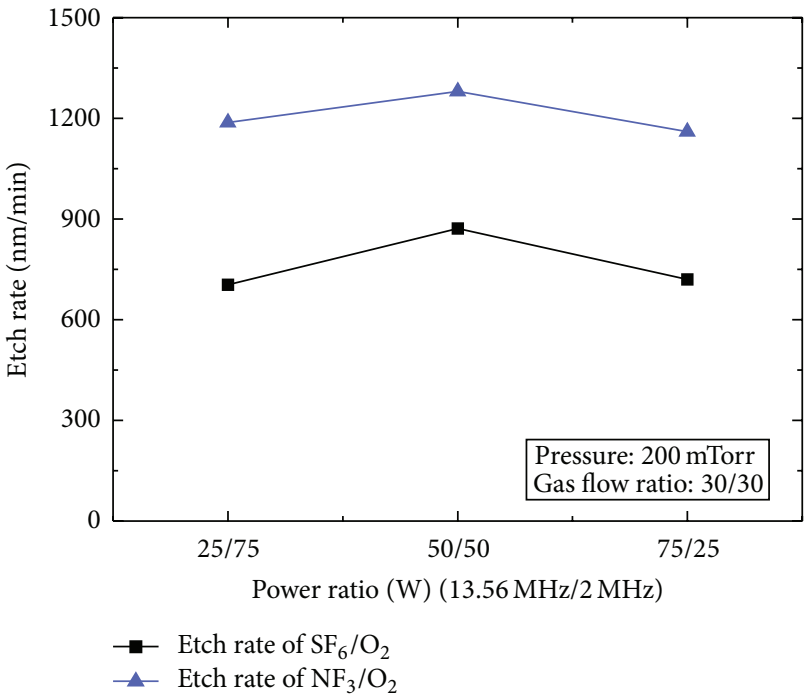

(a)

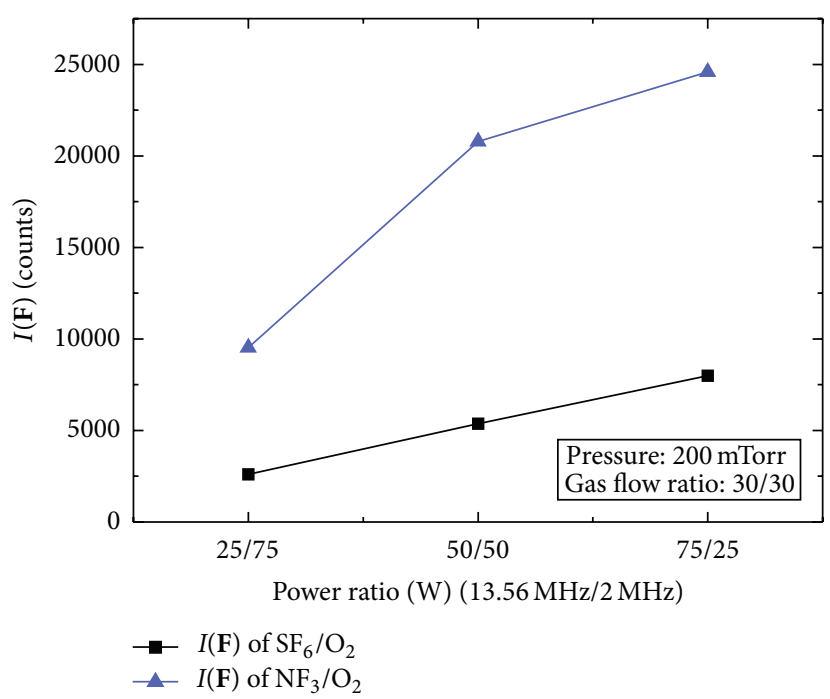

(b)

Figure 4: (a) Etch rates of $\mathrm{SF}_{6} / \mathrm{O}_{2}$ and $\mathrm{NF}_{3} / \mathrm{O}_{2}$ and (b) optical emission intensity of fluorine for $\mathrm{SF}_{6} / \mathrm{O}_{2}$ and $\mathrm{NF}_{3} / \mathrm{O}_{2}$ as a function of power ratio.

a view port on the chamber side wall. A $V$-I probe ( $V$-I probe 4100 by MKS, ENI Products) measured the loads $V$ and $I$ for the RF plasma discharge. The optical emissions were analyzed with a spectrometer. The spectrometer (HR2000+ by Ocean Optics Inc.) with optical resolution of $0.035 \mathrm{~nm}$ and range of 200-1100 nm was used.

Typically, various radicals such as $\mathrm{NF}_{2}$ and $\mathrm{SF}_{5}$ participate in the dry etching processes. However, the optical emission intensity of atomic fluorine was measured to observe the common element between the $\mathrm{SF}_{6}$ and $\mathrm{NF}_{3}$ processes. The emission peaks of atomic fluorine at $658.6 \mathrm{~nm}$ and $703.7 \mathrm{~nm}$ were used [18-20] and the sum of them referred to the optical emission intensities of atomic fluorine $(I(\mathbf{F}))$ in this experiment.

\section{Results and Discussion}

3.1. Results. The dry etching conditions and results are given in Table 1. Figure 2 shows the etching characteristics and optical emission intensities of atomic fluorine $(I(\mathbf{F}))$ obtained using the two gases for different gas flow ratios $\left(\right.$ gas $\left./ \mathrm{O}_{2}\right)$ at a fixed RF power ratio $(13.56 \mathrm{MHz} / 2 \mathrm{MHz})$ of $25 \mathrm{~W} / 75 \mathrm{~W}$ and 200 mTorr. A small increase in $\mathrm{O}_{2}$ flow increased the etch rate, while further increases in the $\mathrm{O}_{2}$ flow rate decreased the etch 


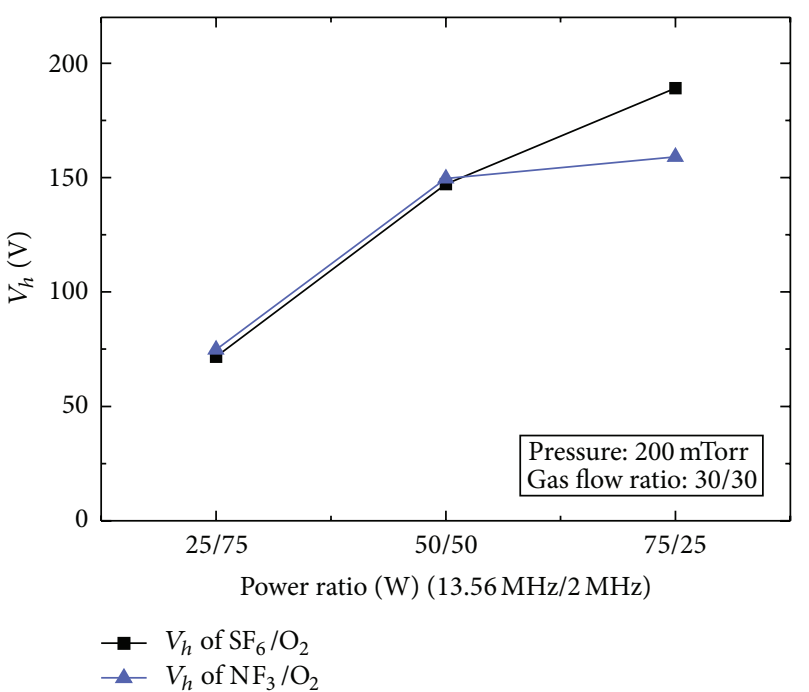

(a)

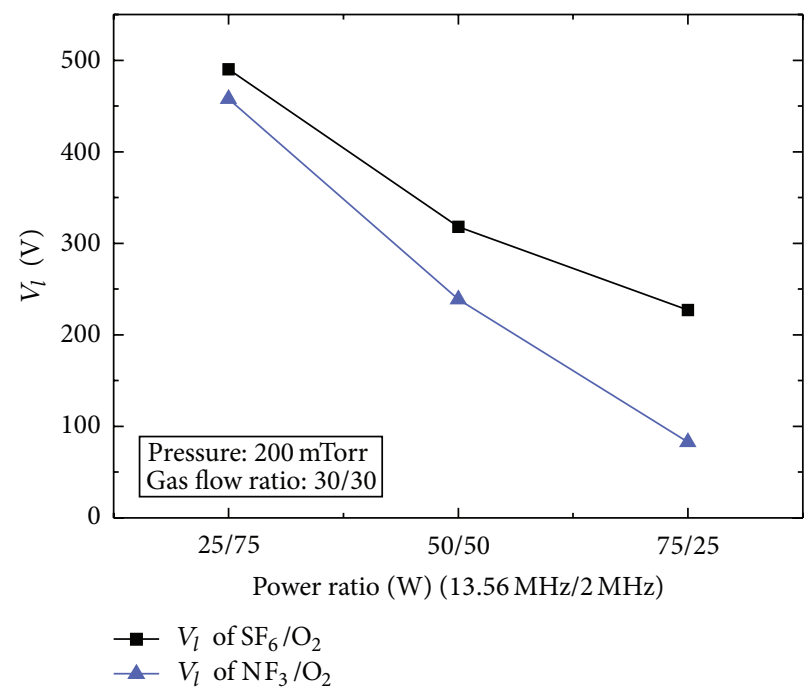

(b)

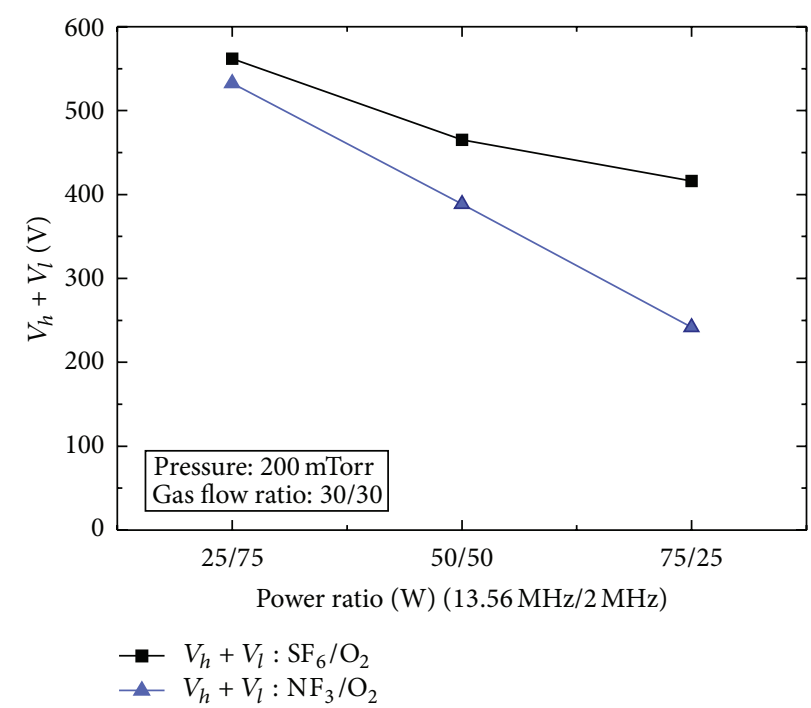

(c)

Figure 5: (a) Voltage of high-frequency RF source $V_{h}$, (b) voltage of low-frequency RF source $V_{l}$, and (c) sum of $V_{h}$ and $V_{l}$ as a function of power ratio.

rate, as is usual [21]. In Figure 2(b), the behavior of $I(\mathbf{F})$ for $\mathrm{SF}_{6} / \mathrm{O}_{2}$ follows the etch rate behavior.

Figure 3 shows the etching characteristics and $I(\mathbf{F})$ for the two gases obtained using different pressures with a power ratio $(13.56 \mathrm{MHz} / 2 \mathrm{MHz})$ of $25 \mathrm{~W} / 75 \mathrm{~W}$ and a gas flow ratio of $30 \mathrm{sccm} / 30 \mathrm{sccm}$. The etch rate and $I(\mathbf{F})$ tended to increase as the pressure increased.

Figure 4 shows the results obtained when the power ratio of high and low RF frequencies was varied with a fixed total power of $100 \mathrm{~W}$ at $200 \mathrm{~m}$ Torr and a gas $/ \mathrm{O}_{2}$ flow ratio of $30 \mathrm{sccm} / 30 \mathrm{sccm}$. Although $I(\mathbf{F})$ increased as the power of the $13.56 \mathrm{MHz}$ source increased, the etch rate did not directly depend on $I(\mathbf{F})$.

In Figure 5, the voltages obtained under the same conditions are shown. As was the case in Figure 4(a), the etch rate did not directly depend on the voltages.
3.2. Discussion. When $\mathrm{SiN}_{x}: \mathrm{H}$ film is etched using fluorinebased gases such as $\mathrm{SF}_{6}$ and $\mathrm{NF}_{3}$, the film is eliminated in the form of $\mathrm{SiF}_{x}$. In this mechanism, the gas-phase reactions that create the reactive species (F) are as follows [22, 23]:

"Reactions of $\mathrm{SF}_{6}$ "

$$
\begin{gathered}
\mathrm{SF}_{6}+\mathrm{e} \longrightarrow \mathrm{SF}_{5}+\mathrm{F}+\mathrm{e} \\
\mathrm{SF}_{6}+\mathrm{e} \longrightarrow \mathrm{SF}_{5}^{+}+\mathrm{F}+2 \mathrm{e} \\
\mathrm{SF}_{6}+\mathrm{e} \longrightarrow \mathrm{SF}_{4}^{+}+2 \mathrm{~F}+2 \mathrm{e} \\
\mathrm{SF}_{6}+\mathrm{e} \longrightarrow \mathrm{SF}_{3}^{+}+3 \mathrm{~F}+2 \mathrm{e}
\end{gathered}
$$


TABle 1: (a) Experimental conditions and results for $\mathrm{SF}_{6}$ (b) experimental conditions and results for $\mathrm{NF}_{3}$.

(a)

\begin{tabular}{|c|c|c|c|c|c|c|c|c|}
\hline \multirow{2}{*}{ Number } & \multicolumn{2}{|c|}{ Power (W) } & \multirow{2}{*}{$\begin{array}{r}\text { Pressure } \\
\text { (mTorr) }\end{array}$} & \multicolumn{2}{|c|}{ Gas $(\mathrm{sccm})$} & \multirow{2}{*}{$\begin{array}{l}\text { Etch rate } \\
(\mathrm{nm} / \mathrm{min})\end{array}$} & \multirow{2}{*}{$\begin{array}{c}13.56(\mathrm{MHz}) \\
\mathrm{Vpp}(\mathrm{V})\end{array}$} & \multirow{2}{*}{$\begin{array}{l}2(\mathrm{MHz}) \\
\operatorname{Vpp}(\mathrm{V})\end{array}$} \\
\hline & $13.56(\mathrm{MHz})$ & $2(\mathrm{MHz})$ & & $\mathrm{SF}_{6}$ & $\mathrm{O}_{2}$ & & & \\
\hline 1 & 25 & 75 & 200 & 30 & 30 & 704 & 71.68 & 490.13 \\
\hline 2 & 50 & 50 & 200 & 30 & 30 & 872 & 147.19 & 318.04 \\
\hline 3 & 75 & 25 & 200 & 30 & 30 & 720 & 189.06 & 227.10 \\
\hline 4 & 25 & 75 & 150 & 30 & 30 & 540 & 74.76 & 476.85 \\
\hline 5 & 25 & 75 & 100 & 30 & 30 & 380 & 84.71 & 589.88 \\
\hline 6 & 25 & 75 & 200 & 30 & 15 & 612 & 71.60 & 490.78 \\
\hline 7 & 25 & 75 & 200 & 30 & 45 & 624 & 73.42 & 483.61 \\
\hline
\end{tabular}

(b)

\begin{tabular}{|c|c|c|c|c|c|c|c|c|}
\hline \multirow{2}{*}{ Number } & \multicolumn{2}{|c|}{ Power $(\mathrm{W})$} & \multirow{2}{*}{$\begin{array}{r}\text { Pressure } \\
\text { (mTorr) }\end{array}$} & \multicolumn{2}{|c|}{ Gas (sccm) } & \multirow{2}{*}{$\begin{array}{l}\text { Etch rate } \\
(\mathrm{nm} / \mathrm{min})\end{array}$} & \multirow{2}{*}{$\begin{array}{c}13.56(\mathrm{MHz}) \\
\mathrm{Vpp}(\mathrm{V})\end{array}$} & \multirow{2}{*}{$\begin{array}{l}2(\mathrm{MHz}) \\
\operatorname{Vpp}(\mathrm{V})\end{array}$} \\
\hline & $13.56(\mathrm{MHz})$ & $2(\mathrm{MHz})$ & & $\mathrm{NF}_{3}$ & $\mathrm{O}_{2}$ & & & \\
\hline 1 & 25 & 75 & 200 & 30 & 30 & 1,188 & 74.85 & 105.86 \\
\hline 2 & 50 & 50 & 200 & 30 & 30 & 1,280 & 149.65 & 211.64 \\
\hline 3 & 75 & 25 & 200 & 30 & 30 & 1,160 & 159.00 & 224.86 \\
\hline 4 & 25 & 75 & 150 & 30 & 30 & 1,040 & 77.96 & 110.26 \\
\hline 5 & 25 & 75 & 100 & 30 & 30 & 768 & 77.24 & 109.24 \\
\hline 6 & 25 & 75 & 200 & 30 & 15 & 870 & 75.63 & 106.96 \\
\hline 7 & 25 & 75 & 200 & 30 & 45 & 912 & 75.99 & 107.48 \\
\hline
\end{tabular}

"Reactions of $\mathrm{NF}_{3}$ "

$$
\begin{aligned}
& \mathrm{NF}_{3}+\mathrm{e} \longrightarrow \mathrm{NF}_{2}+\mathrm{F}+\mathrm{e} \\
& \mathrm{NF}_{2}+\mathrm{e} \longrightarrow \mathrm{NF}+\mathrm{F}+\mathrm{e}
\end{aligned}
$$

Because the different reactions that create the reactive $\mathrm{F}$ cause differences in the etch rate and lead to different characteristics of the $\mathrm{SF}_{6}$ and $\mathrm{NF}_{3}$ processes, the optical emission intensity was observed as an alternative to a quantitative analysis of the reactive $\mathrm{F}$.

In dual-frequency RF discharges, the following relationship between the density of the bulk plasma and the voltage of the RF sources exists [24]:

$$
n_{p} \propto \frac{\omega^{2} V_{\mathrm{rf}}}{\varepsilon_{c}},
$$

where $n_{p}$ is the density of the bulk plasma and $\varepsilon_{c}$ is the collisional energy loss per electron.

In the etching of $\mathrm{Si}$ containing films in fluorine-based plasma, the F-atom density is directly involved in the etching process [25]. Although the plasma density would not be directly proportional to the atomic fluorine density, there would be a strong relation between them. As shown in Figure 3, $I(\mathbf{F})$ increased as the pressure increased. It seems that the increase in pressure led to a higher bulk plasma density, and this higher density caused $I(\mathbf{F})$ to increase. To confirm this reasoning, the $I(\mathbf{F}) \propto \omega^{2} V_{\text {rf }}$ relationship was investigated in Figure 6. In this work, the value of $\omega_{h}^{2} V_{h}$ was dominant, so that $\omega_{h}^{2} V_{h}+\omega_{l}^{2} V_{l} \approx \omega_{h}^{2} V_{h} \gg \omega_{l}^{2} V_{l}$. When the linear fitting model (least square fitting method)

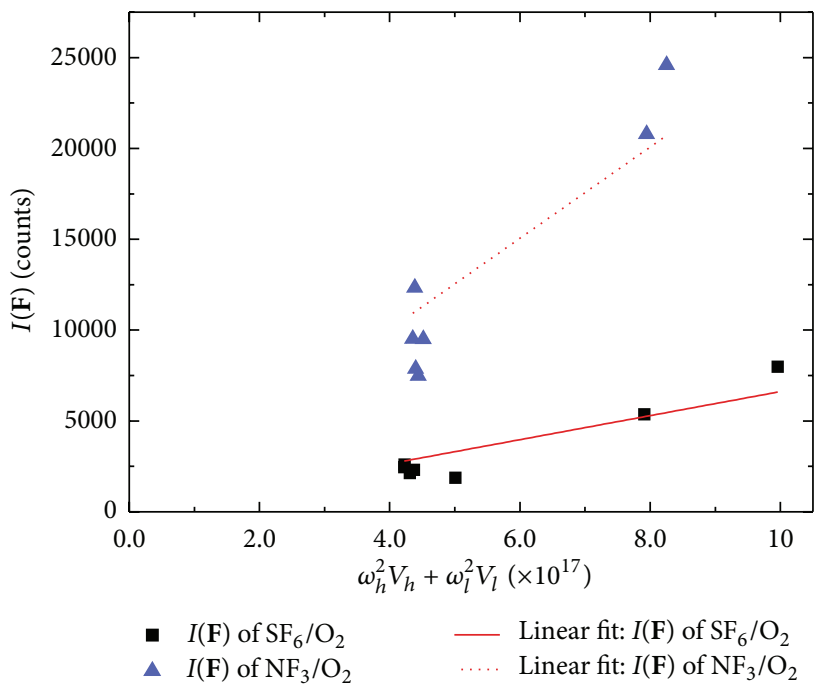

FIGURE 6: Distribution of optical emission intensity of fluorine versus $\omega_{h}^{2} V_{h}+\omega_{l}^{2} V_{l}$.

was applied to Figure 6, different slopes were obtained for $\mathrm{SF}_{6} / \mathrm{O}_{2}$ and $\mathrm{NF}_{3} / \mathrm{O}_{2}$. It is assumed that the different $\varepsilon_{\mathrm{c}}$ values and different reactions for the two gases led to the different slopes. In conclusion, $I(\mathbf{F})$ was proportional to $\omega_{h}^{2} V_{h}+\omega_{l}^{2} V_{l}$, and the density of atomic fluorine $\left(n_{\mathrm{F}}\right)$ could be described as directly dependent on $I(\mathbf{F})$. Figure 7(a) shows the proportional relation between the etch rate and $I(\mathbf{F})$. If we assume that the atomic fluorine density directly depends on $I(\mathbf{F})$, this shows that a relationship exists between the density 


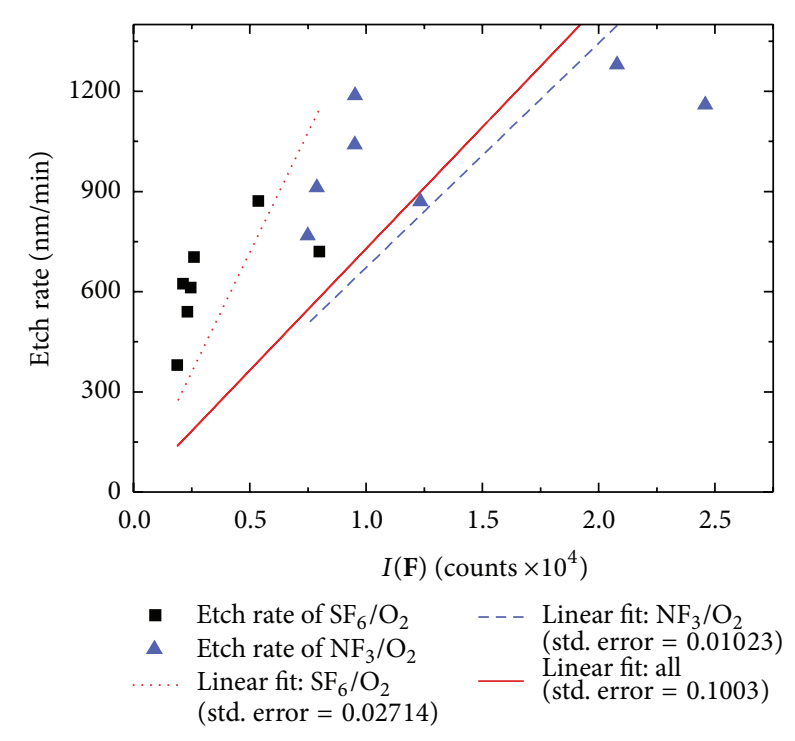

(a)

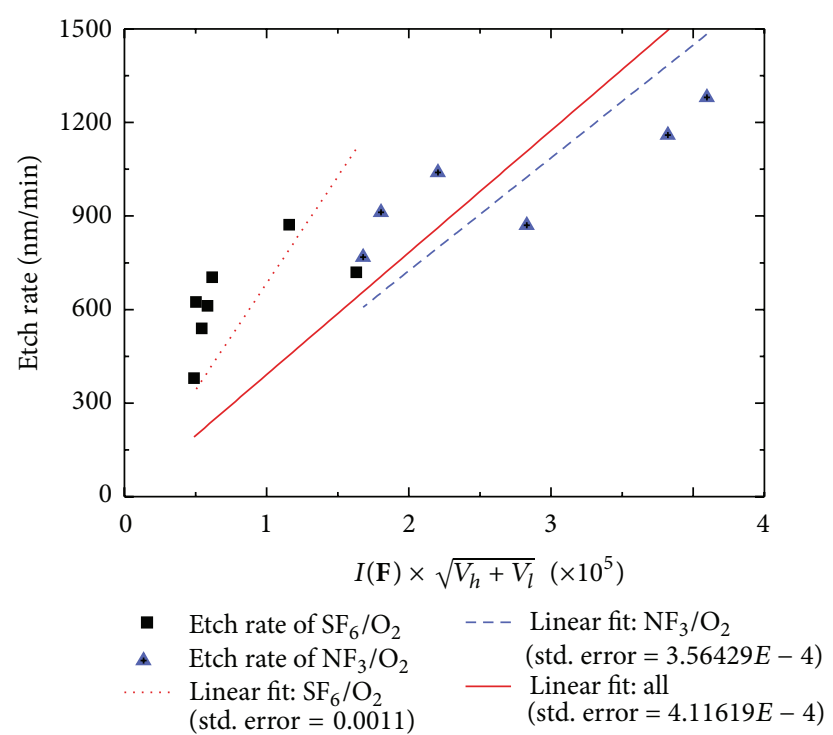

(b)

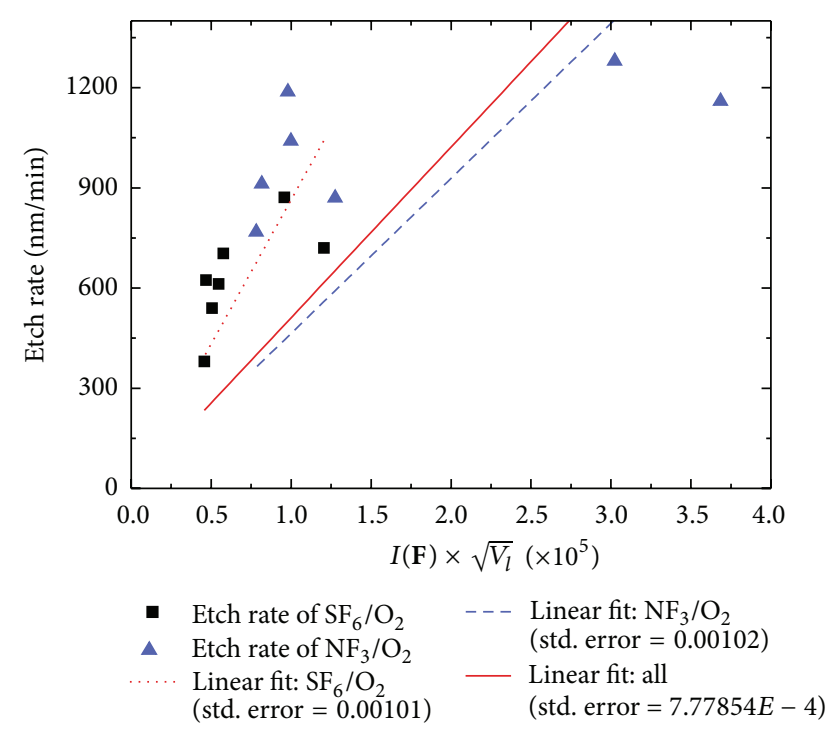

(c)

FIGURE 7: (a) Distribution of etch rate versus $I(\mathbf{F})$, (b) distribution of etch rate versus $I(\mathbf{F}) \times \sqrt{V_{h}+V_{l}}$, and (c) distribution of etch rate versus $I(\mathbf{F}) \times \sqrt{V_{l}}$.

of the atomic fluorine and the $\mathrm{SiN}_{x}: \mathrm{H}$ etch rate. In fact, a number of recent studies have produced similar results to utilize a relation between the OES intensity and plasma density [26-28].

In Figures 4(a) and 5, the etch rate did not depend on the voltage $\left(V_{h}, V_{l}\right.$ or $\left.V_{h}+V_{l}\right)$ directly. In the bulk plasma, the velocity of the fluorine ion was proportional to $\sqrt{V_{h}+V_{l}}$. This increased the velocity of the reactant atom $\left(v_{\mathrm{F}}\right)$ via an ion-neutral momentum transfer collision or charge exchange. However, the etch rate was not dependent on $v_{\mathrm{F}}$ alone. Generally speaking, an etch rate is influenced by the flux of the reactant transported to the substrate. If $n_{\mathrm{F}}$ is related to $I(\mathbf{F})$ and $v_{\mathrm{F}}$ is proportional to $\sqrt{V_{h}+V_{l}}$, the etch rate will be proportional to $I(\mathbf{F}) \times \sqrt{V_{h}+V_{l}}$. Under the same linear fitting model, the relation of the etch rate to $I(\mathbf{F}) \times \sqrt{V_{h}+V_{l}}$ is shown in Figure 7(b). It was found that the standard fitting errors were reduced when the voltage was considered. This shows that the etch rate had a closer relationship with $I(\mathbf{F}) \times$ $\sqrt{V_{h}+V_{l}}$ than it did solely for $I(\mathbf{F})$. In the dual-frequency $\mathrm{CCP}$, it is believed that the bias (lower frequency) power contributed more to the ion energy than the source (higher frequency) power. Therefore, it is believed that the bias power had a greater effect on the etch rate. In Figure 7(c), only the bias power voltage is considered to see the bias power effect. The fitting results were similar to those of Figure $7(\mathrm{~b})$. If the assumption that the velocity of the atomic fluorine was 
affected by voltage is invoked, this result shows that the major contribution on the flux of the atomic fluorine comes from bias power.

\section{Conclusion}

In this paper, the etch characteristics of $\mathrm{SF}_{6} / \mathrm{O}_{2}$ and $\mathrm{NF}_{3} / \mathrm{O}_{2}$ were compared for different process conditions using a CCPRIE system, and the similarities and dissimilarities between the processes using the two gases were analyzed. The etch rate of $\mathrm{SiN}_{x}: \mathrm{H}$ using $\mathrm{NF}_{3} / \mathrm{O}_{2}$ rather than $\mathrm{SF}_{6} / \mathrm{O}_{2}$ increased by 1.4-2.0 times in the same process conditions. These results indicate that the etch time can be reduced to obtain similar results by replacing gases. Because the $\mathrm{GWP}$ of $\mathrm{SF}_{6}$ is 3.1 times higher than that of $\mathrm{NF}_{3}$, the gas replacement can reduce the GWP by factor of $1 / 4.3-1 / 6.2$, while obtaining the same process results.

An optical analysis using an OES showed that the density of the atomic fluorine was dependent on the intensity of the atomic fluorine. By inspecting the relationships between the etch rate of $\mathrm{SiN}_{x}: \mathrm{H}$ and $I(\mathbf{F})$, the effects of atomic fluorine density on the etch rate and its proportionality could be monitored indirectly. A larger $I(\mathbf{F})$ (more abundant atomic fluorine) enabled a capacity to contribute to the etch rate. An electrical analysis using a $V-I$ probe indicated that the velocity of the reactive $\mathrm{F}$ was proportional to $\sqrt{V_{h}+V_{l}}$. The flux of the atomic fluorine was interpreted as $I(\mathbf{F}) \times \sqrt{V_{h}+V_{l}}$, and it was proportional to the etch rate. The importance of the bias power on the etch rate was examined indirectly, and it was concluded that the greatest contribution to the etch rate was from the bias power. This suggests the possibility of utilizing the flux of the atomic fluorine for the simple monitoring parameters (OES and voltages).

\section{Conflict of Interests}

The authors declare that there is no conflict of interests regarding the publication of this paper.

\section{Acknowledgments}

This work was supported in part by the International collaborative R\&D program (N0000678) and by the Industrial Strategic Technology Development Program (10041681) funded by the Ministry of Trade, Industry and Energy of Korea.

\section{References}

[1] D. J. Kim, Y. B. Yun, and J. Y. Hwang, "Role of $\mathrm{N}_{2}$ during chemical dry etching of silicon oxide layers using $\mathrm{NF}_{3} / \mathrm{N}_{2} / \mathrm{Ar}$ remote plasmas," Microelectronic Engineering, vol. 84, no. 4, pp. 560-566, 2007.

[2] B. E. E. Kastenmeier, "Remote plasma etching of silicon nitride and silicon dioxide using $\mathrm{NF}_{3} / \mathrm{O}_{2}$ gas mixtures," Journal of Vacuum Science and Technology A, vol. 16, no. 4, pp. 2047-2056, 1998.
[3] P. Machima and N. Hershkowitz, "SiO${ }_{2}$ and $\mathrm{Si}_{3} \mathrm{~N}_{4}$ etch mechanisms in $\mathrm{NF}_{3}$ /hydrocarbon plasma," Journal of Physics $D$, vol. 39, no. 4, pp. 673-684, 2006.

[4] G. Agarwal, S. D. Iuliis, L. Serenelli, En. Salza, and M. Tucci, "Dry texturing of mc-Si wafers," Physica Status Solidi C, vol. 8, no. 3, pp. 903-906, 2011.

[5] C. Reyes-Betanzo and S. A. Moshkalyyov, "Mechanisms of silicon nitride etching by electron cyclotron resonance plasmas using $\mathrm{SF}_{6}$ - and $\mathrm{NF}_{3}$-based gas mixtures," Journal of Vacuum Science and Technology A, vol. 22, p. 1513, 2004.

[6] J. H. Kim and Y. C. Hong, "Simple microwave plasma source at atmospheric pressure," Journal of the Korean Physical Society, vol. 42, p. S876, 2003.

[7] J. H. Kim and C. H. Oh, "Effect of N-based gases to $\mathrm{C}_{3} \mathrm{~F}_{8} / \mathrm{O}_{2}$ on global warming during silicon nitride PECVD chamber cleaning using a remote plasma source," Journal of the Korean Physical Society, vol. 42, p. S800, 2003.

[8] H. Hsueh, R. T. McGrath, B. Ji, B. S. Felker, J. G. Langan, and E. J. Karwacki, "Ion energy distributions and optical emission spectra in $\mathrm{NF}_{3}$-based process chamber cleaning plasmas," Journal of Vacuum Science and Technology B, vol. 19, no. 4, pp. 1346-1357, 2001.

[9] P. Brault and P. Ranson, "Analysis of $\mathrm{SF}_{6}$ and $\mathrm{F}_{2}$ plasma etched silicon surfaces: an X-ray photoelectron spectroscopy investigation," Applied Physics Letters, vol. 57, p. 2649, 1990.

[10] Y. B. Yun, S. M. Park, and N.-E. Lee, "Effect of plasma modulation on $\mathrm{Si}$ chemical dry etching in $\mathrm{F}_{2}$ remote plasmas," Journal of the Korean Physical Society, vol. 53, no. 5, pp. 23862390, 2008.

[11] S. Nakamura and M. Itano, "Comparative studies of perfluorocarbon alternative gas plasmas for contact hole etch," Japanese Journal of Applied Physics, vol. 42, pp. 5759-5764, 2003.

[12] Ch. Steinbrchel, H. W. Lehmann, and K. Frick, "Mechanism of dry etching of silicon dioxide. A case of direct reactive ion etching," Journal of the Electrochemical Society, vol. 132, no. 1, pp. 180-186, 1985.

[13] F. Fracassi, R. D’Agostino, A. Fornelli, and T. Shirafuji, "Dry etching of $\mathrm{SiO}_{2}$ thin films with perfluoropropenoxide- $\mathrm{O}_{2}$ and perfluoropropene- $\mathrm{O}_{2}$ plasmas," Journal of Applied Physics, vol. 41, pp. 6287-6290, 2002.

[14] W. T. Tsai, H. P. Chen, and W. Hsien, "A review of uses, environmental hazards and recovery/recycle technologies of perfluorocarbons (PFCs) emissions from the semiconductor manufacturing processes," Journal of Loss Prevention in the Process Industries, vol. 15, no. 2, pp. 65-75, 2002.

[15] J. G. Owens, "Low GWP alternatives to HFCs and PFCs," in Proceedings of the 1999 Taipei International Conference on Atmosphere Protection, Taipei, Taiwan, 1999.

[16] L. C. Pruette, S. M. Karecki, R. Reif et al., "Evaluation of trifluoroacetic anhydride as an alternative plasma enhanced chemical vapor deposition chamber clean chemistry," Journal of Vacuum Science and Technology A, vol. 16, pp. 1577-1581, 1998.

[17] H. Reichardt, A. Frenzel, and K. Schober, "Environmentally friendly wafer production: $\mathrm{NF}_{3}$ remote microwave plasma for chamber cleaning," Microelectronic Engineering, vol. 56, no. 1-2, pp. 73-76, 2001.

[18] S. Q. Gu, R. Fujimoto, and P. McGrath, "Impact of F species on plasma charge damage in a RF asher," in Proceedings of the 
7th International Symposium on Plasma- and Process-Induced Damage, Maui, Hawaii, USA, 2002.

[19] A. Matsutani, H. Ohtsuki, and F. Koyama, "Reactive ion etching of Si using Ar/ $\mathrm{F}_{2}$ plasma," Japanese Journal of Applied Physics, vol. 49, Article ID 06GH05-2, 3 pages, 2010.

[20] G. Bruno, P. Capezzuto, P. Manodoro et al., "On the use of NF3 plasmas for amorphous silicon ablation," in Proceedings of the 11th International Symposium on Plasma Chemistry, p. 875, Loughborough, UK, 1993.

[21] M. A. Lieberman and A. J. Lichtenberg, Principles of Plasma Discharges and Materials Processing, p. 596, John Wiley \& Sons, Hoboken, NJ, USA, 2005.

[22] G. Kokkoris, A. Panagiotopoulos, A. Goodyear, M. Cooke, and E. Gogolides, "A global model for $\mathrm{SF}_{6}$ plasmas coupling reaction kinetics in the gas phase and on the surface of the reactor walls," Journal of Physics D, vol. 42, Article ID 055209, 5 pages, 2009.

[23] B. Bai, An experimental study and modeling of TransformerCoupled Toroidal Plasma processing of materials [Ph.D. thesis], Massachusetts Institute of Technology, Boston, Mass, USA, 2006.

[24] M. A. Lieberman and A. J. Lichtenberg, Principles of Plasma Discharges and Materials Processing, p. 410, John Wiley \& Sons, Hoboken, NJ, USA, 2005.

[25] C. J. Mogab, “The loading effect in plasma etching," Journal of the Electrochemical Society, vol. 124, no. 8, pp. 1262-1268, 1977.

[26] I. P. Herman, "Optical diagnostics for thin film processing," Annual Review of Physical Chemistry, vol. 54, pp. 277-305, 2003.

[27] Z. Chen, V. M. Donnelly, D. J. Economou et al., "Measurement of electron temperatures and electron energy distribution functions in dual frequency capacitively coupled $\mathrm{CF}_{4} / \mathrm{O}_{2}$ plasmas using trace rare gases optical emission spectroscopy," Journal of Vacuum Science and Technology A, vol. 27, pp. 1159-1165, 2009.

[28] W. Liu, A. Zhu, X. Li et al., "Determination of plasma parameters in a dual-frequency capacitively coupled $\mathrm{CF}_{4}$ plasma using optical emission spectroscopy," Plasma Science and Technology, vol. 15, no. 9, p. 885, 2013. 

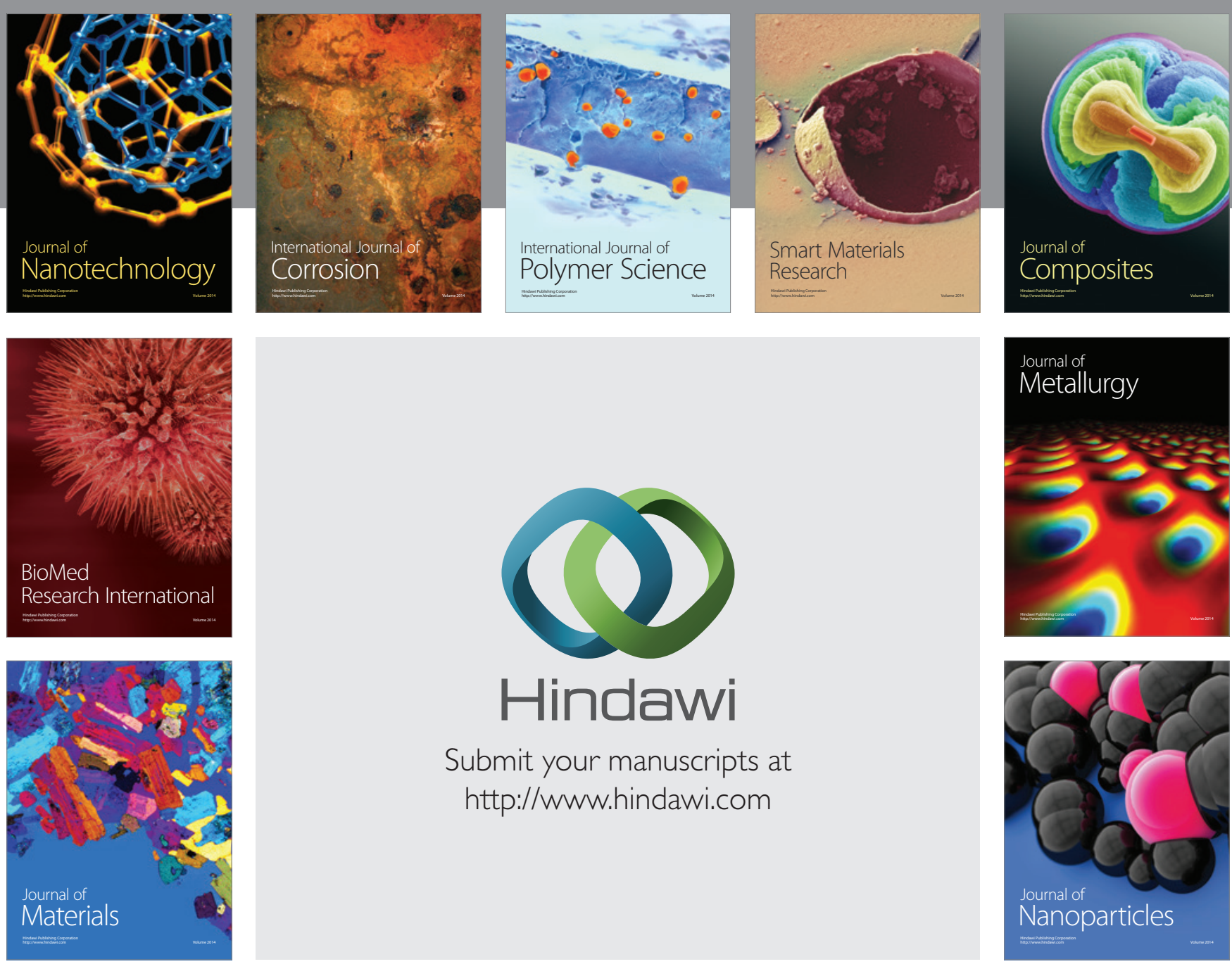

Submit your manuscripts at http://www.hindawi.com
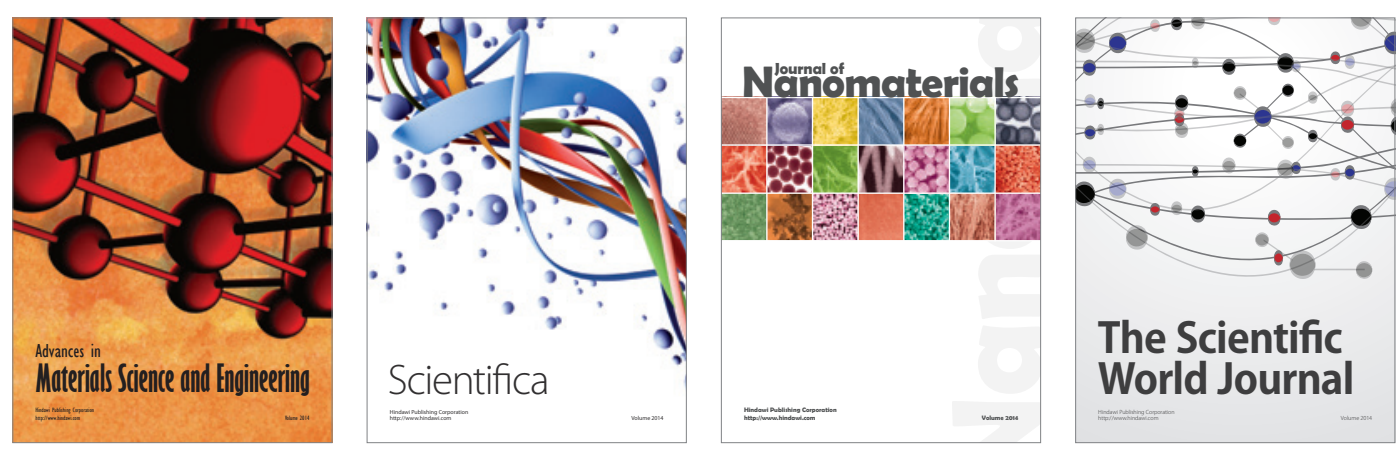

\section{The Scientific World Journal}
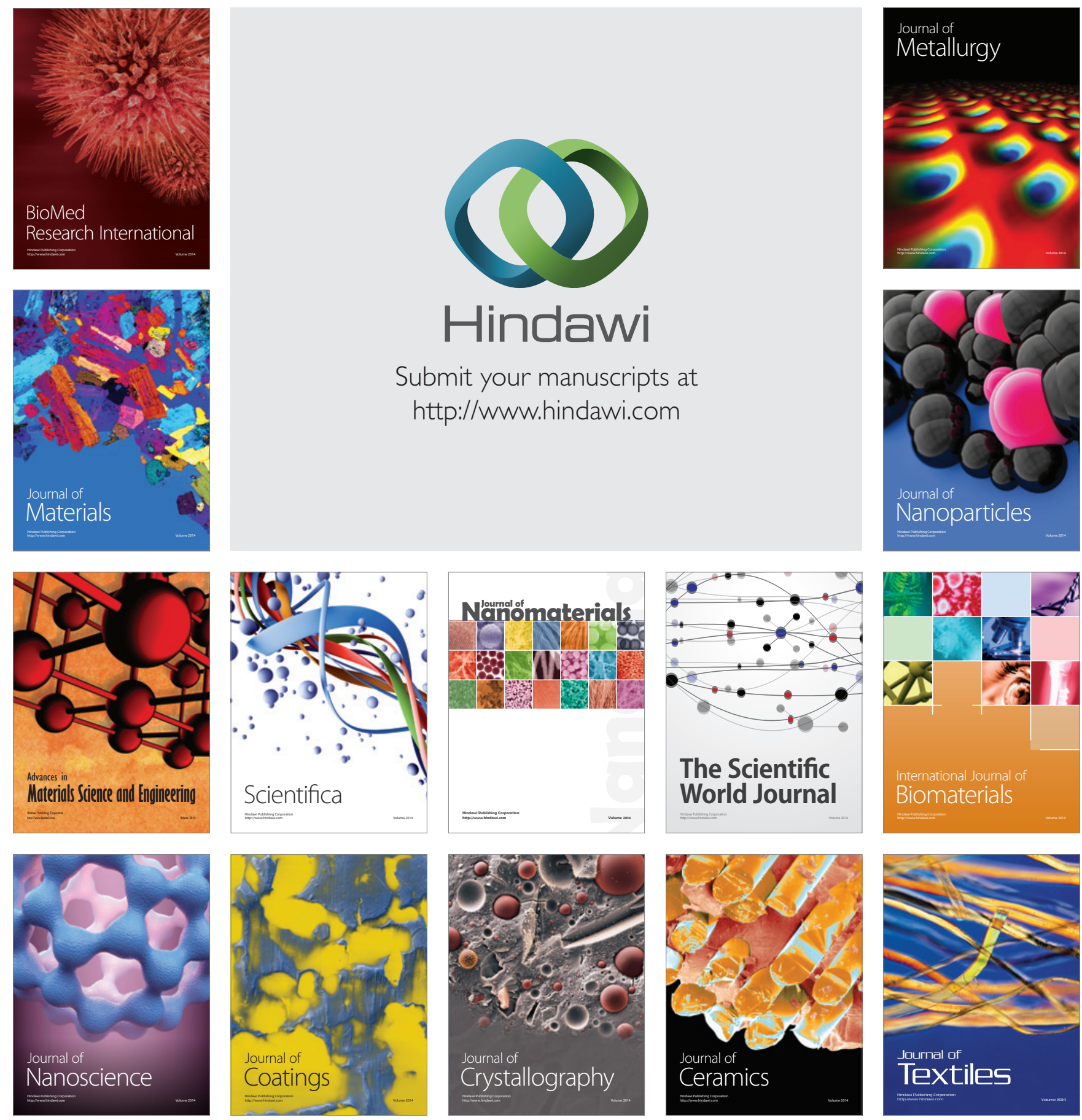